\title{
Effects of Principal's Positive Leadership on Job Insecurity and School Effectiveness in China
}

\author{
Zhaoyang $\mathrm{Xu}^{1,2}$, Chia-Ching Tu ${ }^{3^{*}}$ \\ ${ }^{1}$ Doctoral Candidate in Education Management at China-ASEAN International College, Dhurakij Pundit University, THAILAND \\ ${ }^{2}$ Zhengzhou Institute of Industrial Application Technology, Zhengzhou, CHINA \\ ${ }^{3}$ Educational Management Department, CHINA-ASEAN International College, Dhurakij Pundit University, THAILAND
}

Received 25 June 2019 - Revised 2 November 2019 - Accepted 28 November 2019

\begin{abstract}
This study took the teachers of private colleges and universities in Henan Province of China as the research objects, discussed the influence of the teacher perceived principal's positive leadership on the school effectiveness, and explored the moderating role of job insecurity. A total of 450 samples were collected from five private universities in Henan Province, China in the method of convenient sampling, with 441 samples valid and the valid rate of $98 \%$. SPSS 22 and AMOS 21 statistical software were conducted for processing, and the research results showed that teacher perceived principal's positive leadership has a positive and significant impact on the school effectiveness in private colleges and universities, that the job insecurity of private college teachers has a negative and significant impact on school effectiveness, and that job insecurity plays a moderating role in the influence of teacher perceived principal's positive leadership on the school effectiveness in private colleges and universities.
\end{abstract}

Keywords: teacher perceived principal's positive leadership; job insecurity; school effectiveness; private colleges and universities

\section{INTRODUCTION}

In the era of knowledge economy, it is well believed in the world that priority must be given to the development of education. School effectiveness has always been regarded as a guide to the quality of education, and improving school effectiveness is also the main goal of education reform (Hou, 2002). As a saying goes, "what kind of principals, what kind of schools", which indicates that the leadership of a principal has a close relationship with the development of the college. Cameron (2012) pointed out that positive leadership is based on positivity, emphasizing affirmative orientation, and focusing on good virtues, so as to promote the positive results of individuals and organizations, and to achieve an extraordinary high performance. It can promote a positive communication among members, create a positive atmosphere for the organization, establish a positive relationship between members, and build a shared vision and meaning of the organization (Donaldson \& Ko, 2010; Xie, 2011). Thus, the positive leadership of school leaders is an important factor which affects the school effectiveness.

Luthans, Avolio, Avey, and Norman (2007) emphasized that the psychological state of the members has a greater impact on job performance in an organization. However, technological changes and fierce competition have forced organizations to make changes such as layoffs, restructuring, and acquisitions, so as to survive and develop. These changes will bring the organization members a sense of insecurity about future jobs (Hu \& Zuo, 2007). Job insecurity has gradually attracted the attention of theoretical researchers to conduct deep research, and it has also become an important focus of organizational behavior and health psychology (Wang, Wu, Wang, \& Wu, 2018). Knowledge staff's concerns about the quality and the stability of employment relationships are the source of stress (Sverke \& Hellgren, 2002). The job insecurity has an negative impact on employees' work attitude, work and innovation, and job performance (Zhu \& Hu, 2014), which will reduce employee's job satisfaction, organizational trust, etc., raise employee's demission tendency and affect the performance of the organizations, thus heavily

(C) 2019 by the authors; licensee Modestum Ltd., UK. This article is an open access article distributed under the terms and conditions of the Creative Commons Attribution License (http://creativecommons.org/licenses/by/4.0/). 《13525581386@163.com \ chia-ching.tu@dpu.ac.th (*Correspondence) 


\section{Contribution of this paper to the literature}

- This study shows that job insecurity is the teacher's awareness of the principal's active leadership and school effectiveness.

- For the school administration, if a teacher believes that the principal's active leadership ability is high, Principals can improve school efficiency by reducing insecurity at work.

- In school affairs, principals can help teachers reduce insecurity at work and improve their positive perception of the school.

affecting the enterprise (Ashford \& Bobko, 1989). It can be seen that the sense of job insecurity has a significant impact on the attitudes and behaviors of employees and on the overall development of the company, and will undoubtedly attract more and more attention from the business community and the academic community.

At present, there is a certain degree of job insecurity among college teachers in China, which is mainly reflected in the persistent concern about job expectations, and has a negative impact on job performance and engagement. Job insecurity has become a key factor affecting school effectiveness (Zhang, Lin, \& Zhang, 2014). Private colleges and universities play an important role in higher education in China, but they also face a growing competitive education market. It is necessary to find effective ways to improve school effectiveness and to lay the top priority on enhancing the competitiveness for private colleges and universities. The private college teachers are responsible for teaching, scientific research and social services, their knowledge level and intelligence level are very high, and most of them are active, have a strong sense of autonomy and clear goals, and strive to achieve self-worth (Zhao, $\mathrm{Li}$, \& Tan, 2007). The job insecurities of teachers in private colleges and universities affect the teaching quality. In recent years, the employee's job insecurity has been paid attention in all walks of life, but the research on college teachers is not deep (Chen, 2019). Therefore, deeply investigating job insecurity among teachers in private colleges and universities and exploring the role in the process of teacher perceived principal's positive leadership influencing school effectiveness have an significant value in understanding the current psychological and working conditions of teachers in Chinese private colleges and universities, and in optimizing and improving the reform direction of educational management system.

In summary, the principal's positive leadership and the teachers' job insecurity are the important factors which will influence the school effectiveness. Therefore, this study is based on the Chinese private higher education, and tries to explore the effect of teacher perceived principal's positive leadership through the method of empirical investigation. However, Zhang, Zhang and Zhu (2009) suggested that teachers' perspective should be encouraged in exploring the relationship between principal leadership and school effectiveness, so as to discover the relationship with school effectiveness. Teachers' job insecurity plays an important role in the influence mechanism of teacher perceived principal's positive leadership on school effectiveness. And it is of great significance to further discuss the role of teachers' job insecurity between them, in order to provide reference for the improvement of school effectiveness.

\section{LITERATURE REVIEW}

School effectiveness means that school responds to the pressures and needs of internal and external environments, effectively uses material and human resources, integrates the school system, creates a good atmosphere, and achieves high quality administrative, teacher, student and parent effectiveness, so as to reach the purpose of college education (Hu \& Huang, 2007). Creating a school with all-round effectiveness is the goal of all educators in the process of education reform (Qiu, 2003). The principals of colleges and universities can lead teachers and students to promote the development of administrative affairs, improve school effectiveness, and achieve educational goals (Cameron, 2008), and it should be pointed out that positive leadership, as one of the emerging leadership theories, can effectively promote the development of colleges and universities. Positive leadership is a very important and effective principal leadership theory. It emphasizes the positive atmosphere, positive relationship, positive communication, and positive meaning, which is the effective practice of the principal (Xie, 2011). In the present education of colleges and universities, the requirements for quality and quantity and the improvement of efficiency are more urgent, so it is necessary to implement positive leadership behavior in the education of colleges and universities.

That teachers perceive principal can create a positive atmosphere, set the positive vision, communicate with teachers with positive emotions and thoughts at any time can establish a positive interpersonal relationship, better meet the working needs of teachers and help them realize self-worth, so as to reach the goals together in colleges and universities (Cameron, 2012).

Some studies suggest that college leaders have an important impact on school effectiveness (Blau \& Presser, 2013; Hu \& Huang, 2007), and their administration and communication play an irreplaceable role in improving 
school effectiveness (Lukaš \& Jankovic, 2014). The principals' ability to administration and communication has a direct positive effect on management effectiveness and teacher effectiveness (Zhao, 2016). It can promote the best state of members and improve the school effectiveness that college principals use positive thinking and strategies, acknowledgement and apply the potential and advantages of the members, and make good use of the power of motivation (Lin, 2010). Positive leadership can create the performance that exceeds normal or expected performance, promote the productivity, profit, quality, reform and innovation, employee's advice, and bring benefits to individuals in physiology, emotions, interpersonal relationships, and learning (Cameron, 2013; Luo \& Zhang, 2018). Effective use of positive leadership will help supervisors become effective leaders and create greater effectiveness $(\mathrm{Wu}, 2013)$. It can be seen that principal's leadership is a key factor in school effectiveness and has a positive impact on school effectiveness. Based on the above analysis, hypothesis $\mathrm{H} 1$ was proposed in this study: the teachers perceived principals' positive leadership has a positive effect on school effectiveness in private colleges and universities.

However, technological change and fierce competition have prompted organizations to make changes to survive and thrive, which will make members feel insecure about future work (Hu \& Zuo, 2007). $\mathrm{Hu}$ and $\mathrm{Li}$ (2010) believe that job insecurity is the employee perceived degree of threat to work stability and future development. It is a main source of work stress and will seriously affect individual's psychology and behavior (Feng, Lu, Xiao), 2008), and it also causes negative effects from psychological stress to physical illness, finally affecting work performance and even the overall performance of the unit (Greenhalgh \& Rosenblatt, 1984; Roskies \& Louis-Guerin, 1990). Job insecurity has a significant positive impact on task performance, and the insecurity such as job loss has a significant negative impact on interpersonal promotion in new employee's performance (Zhao \& Liang, 2015). Feng et al. (2008) conducted an empirical study on the relationship between job insecurity and employee's well-being and job performance, and it is found that employee's job insecurity has a significant negative impact on performance. It has different degrees of influence on the individual's attitudes and behaviors, as well as physical and mental health, which in turn affects the improvement of effectiveness and the implementation of reform in organizations (Jiang, Chen, 2011). Insecurity can lead to negative emotions such as worrying, anxiety, finally causing emotional exhaustion (Piccoli \& Witte, 2015) and undermining citizenship behavior in organizations (Lam, Liang, Ashford, \& Lee, 2015). In contrast, in a safe working environment, employees feel comfortable and free to work. They trust leaders and actively contribute to the organization (Bemtson, Naswall, \& Sverke, 2010). According to the above analysis, hypothesis $\mathrm{H} 2$ is proposed in this study: the sense of job insecurity in private college teachers has a significant negative impact on school effectiveness.

According to the Theory of Social Information Processing, the workplace environment provides social information to influence employee's attitudes and behaviors. Employees perceive the workplace environment through the interaction with others, thus affecting employee's subsequent attitudes, behaviors and performance (Salancik \& Pfeffer, 1978). In private colleges and universities, teachers perceive the working environment, and job insecurity is one of the most important perceptions. The degree of job insecurity will be influenced by the leadership style and philosophy in colleges and universities, which will affect the teachers' effectiveness in all aspects of the college work.

$\mathrm{Yu}$ (2017) pointed out in the concept and development of school efficiency that effective improvement of school effectiveness requires a positive interaction mechanism between principals, faculty, parents and the community. Abdullah (2009) suggests that the positive behavior of leaders in an organization contributes to the psychological improvement of members within the organization. Zhong (2011) pointed out that the headmaster of the primary school has positive influence on the efficiency of school's innovation and management. Positive leadership can create performance that exceeds normal or expected performance, and promote productivity, profitability, quality, innovation, and customer loyalty, as well as bring individuals the benefits in physiology, emotions, brain function, interpersonal relationships, learning, etc. (Cameron, 2013). Effective use of positive leadership will help supervisors become effective leaders and create greater effectiveness $(\mathrm{Wu}, 2013)$. The relationship between job insecurity and employee's performance depends on the nature of the business and the trust of employees (Wong, Wong, Ngo, \& Lui, 2005). Hu and Zuo (2007) indicate that insecurity in quantitative work can significantly predict the negative impact of task performance, and that insecurity in quality work can significantly predict the negative impact of task performance and peripheral performance.

$\mathrm{Hu}$ and Zuo (2007) pointed out in the research of enterprise employees that work insecurity has a moderating effect between political perception and commitment in organizations; work insecurity negatively moderates the relationship between leadership - member exchange and responsibility, professional mission (Zhang, Jin, \& Jiang, 2017). According to the concept of moderator variables, different levels of moderator variables have different effects of independent variables on dependent variables (Wen, Zhang, \& Hou, 2006). In summary, both teachers perceiving principal's leadership and job insecurity can have an impact on school effectiveness, and effective school performance requires the establishment of a positive interaction between principals, faculty, parents, and communities $(\mathrm{Yu}, 2017)$. It can be seen that the teacher perceived principal's positive leadership and job insecurity 


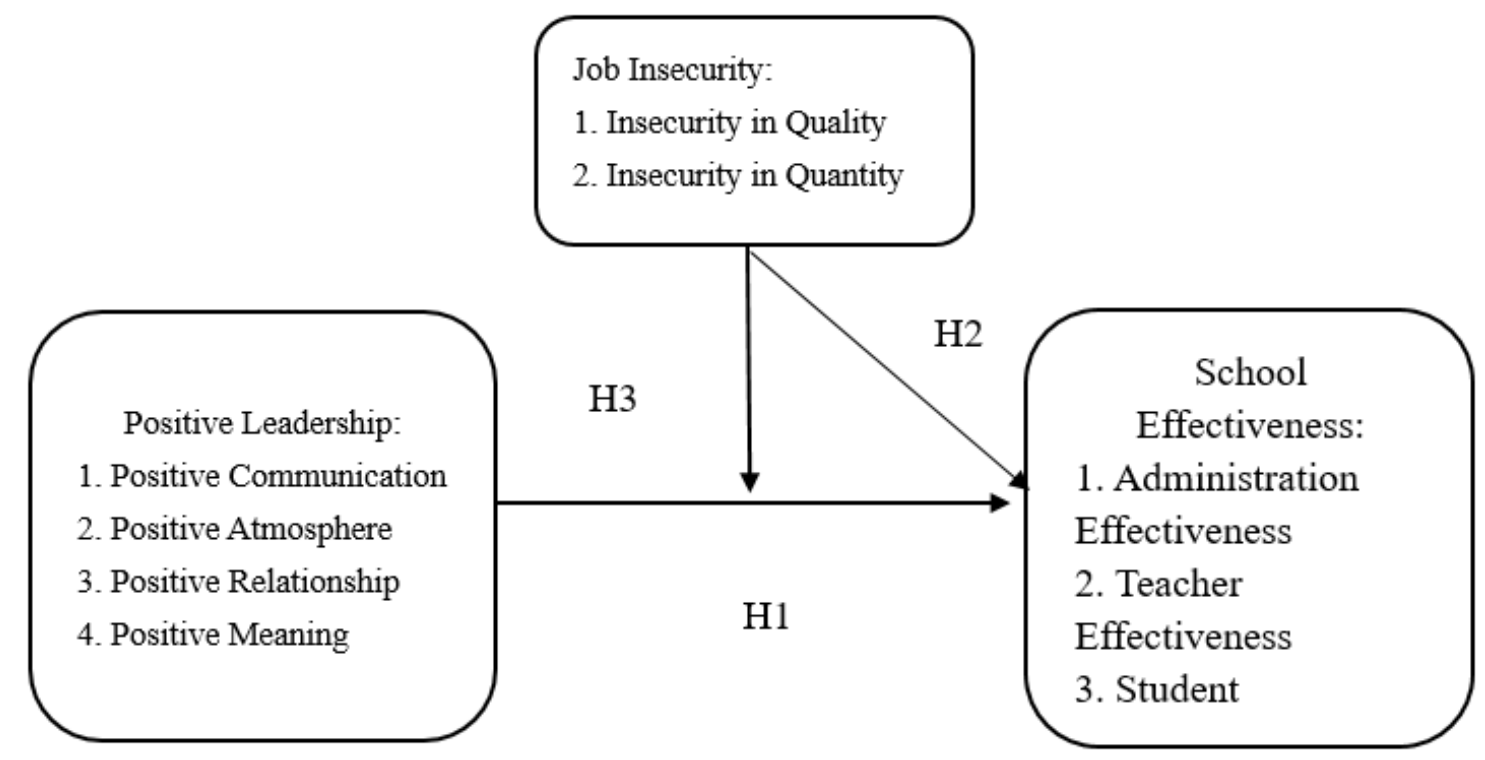

Figure 1. Study Frame Diagram

can interact and affect school effectiveness. Therefore, hypothesis H3 is proposed in this study: the sense of job insecurity among private college teachers has a moderating role between the perceived principal's positive leadership and school effectiveness.

\section{STUDY METHODS}

\section{The Framework of Study}

The framework of study is proposed according to the literature review and analysis (Figure 1). Hypothesis H1: Exploring the influence of teachers perceived principal's positive leadership on the school effectiveness in colleges and universities. Hypothesis H2: Exploring the impact of job insecurity on school effectiveness in teachers of private colleges and universities. Hypothesis H3: Exploring whether teachers' job insecurities in private colleges and universities have a moderating role between teachers perceived principal's positive leadership and school effectiveness.

\section{The Objects of Study}

By adopting the convenient sampling in non-random sampling methods, the questionnaires were sent to the heads of the human resources departments and teaching departments of 5 private universities in the form of online questionnaires, and the teachers of the 5 universities were asked to fill out the questionnaires. A total of 450 questionnaires were distributed and 441 valid questionnaires were returned, with an effective rate of $98.00 \%$. The results showed that in terms of gender, there were 157 male teachers, accounting for $35.60 \%$ of the samples, 284 female teachers, accounting for $64.40 \%$ of the samples. In terms of professional titles, 161 were teaching assistants, accounting for $36.50 \%$ of the samples, 173 lecturers, accounting for $39.20 \%$ of the samples, 51 associate professors, accounting for $11.60 \%$ of the samples, and 56 professors, accounting for $12.70 \%$ of the samples.

\section{The Tools of Study}

Perceived Principal's Positive Leadership Scale (Xie, 2011) is adopted in this study to conduct a questionnaire survey, which included the four dimensions of positive atmosphere, positive relationship, positive communication, and positive meaning; the scale was scored using Likert 5 points and divided into 1-5 points. 1 point represents extreme inconsistent, and 5 points represent very consistent. Higher score means that the degree of teacher perceived principal's positive leadership is higher. In this experiment, Cronbach's a reached 0.97, and the explanatory variation was $79.33 \%$.

Job Insecurity Questionnaire compiled by Hellgren, Sverke, and Isaksson, (1999) is adopted too and divided into two dimensions of quantitative job insecurity and qualitative job insecurity; the scale is scored by Likert 5 points. From 1 point to 5 points, 1 point means extreme inconsistent, and 5 points means very consistent. Higher 
Table 1. Actual Fitness Analysis Table of the Scales

\begin{tabular}{|c|c|c|c|c|c|c|c|}
\hline & $\chi^{2} / \mathrm{df}$ & RMR & NFI & CFI & RFI & PNFI & PCFI \\
\hline Standard & $<5.00$ & $\leqq .080$ & $\geqq .80$ & $\geqq .90$ & $\geqq .90$ & $\geqq .50$ & $\geqq .50$ \\
\hline Perceived Principal's Positive Leadership & 7.88 & 0.01 & 0.95 & 0.96 & 0.94 & 0.74 & 0.75 \\
\hline Job Insecurity & 12.59 & 0.04 & 0.94 & 0.95 & 0.92 & 0.64 & 0.64 \\
\hline Perceived School Effectiveness & 6.97 & 0.03 & 0.95 & 0.95 & 0.93 & 0.76 & 0.76 \\
\hline
\end{tabular}

Subscript: $\chi^{2} / \mathrm{df}$ and RMR are absolute fit index, NFI, CFI, RFI are incremental fit index, and PNFI, PCFI are streamlined fit index

Table 2. Verification Analysis and Reliability Analysis of the Overall Questionnaires

\begin{tabular}{|c|c|c|c|c|c|}
\hline Study Tools & Dimensions & Factor Load & CR & AVE & Cronbach's $\alpha$ \\
\hline \multirow{4}{*}{$\begin{array}{l}\text { Perceived Principal's } \\
\text { Positive Leadership }\end{array}$} & Positive Atmosphere & $0.89-0.90$ & 0.94 & 0.80 & 0.94 \\
\hline & Positive Relationship & $0.88-0.92$ & 0.93 & 0.81 & 0.93 \\
\hline & Positive Communication & $0.89-0.93$ & 0.94 & 0.83 & 0.94 \\
\hline & Positive Meaning & $0.89-0.91$ & 0.94 & 0.81 & 0.94 \\
\hline \multirow{2}{*}{ Job Insecurity } & Qualitative Job Insecurity & $0.83-0.87$ & 0.92 & 0.72 & 0.92 \\
\hline & Quantitative Job Insecurity & $0.65-0.91$ & 0.83 & 0.63 & 0.82 \\
\hline \multirow{4}{*}{ School Effectiveness } & Administration Effectiveness & $0.73-0.89$ & 0.88 & 0.71 & 0.88 \\
\hline & Teacher Effectiveness & $0.80-0.86$ & 0.91 & 0.71 & 0.91 \\
\hline & Student Effectiveness & $0.80-0.89$ & 0.93 & 0.75 & 0.94 \\
\hline & Social Effectiveness & $0.91-0.95$ & 0.95 & 0.86 & 0.95 \\
\hline
\end{tabular}

Subscript: 1. All the above factors are significant ${ }^{* * *} p<0.001$

2. $C R$ is a combine variable; AVE is a mean variation extraction

score means that the degree of teachers' job insecurity is higher. In this test, Cronbach's a reached 0.92, and the explanatory variation was $66.76 \%$.

School Effectiveness Scale compiled by Zhao (2016) includes four dimensions: management effectiveness, teacher effectiveness, student effectiveness, and social effectiveness. The scale uses Likert 5 points, ranging from 1 to 5 points. 1 point represents very inconsistent, and 5 points are very consistent. Higher score means that the degree of teacher's perceived school effectiveness is higher. In this test, Cronbach's a reached 0.96, and the explanatory variation was $67.40 \%$.

In this study, the validity of each scale was tested by confirmatory factor analysis (CFA). The sample data needs to conform to the normal distribution in CFA verification. According to the scale, that the absolute value of the skew was less than 3 and the absolute value of the kurtosis was less than 10 can be considered as normal data (Kline, 1998). After measurement, the skewness coefficient is -1.34 , the kurtosis coefficient is 2.12 in the teachers' perceived principal's positive leadership scale; the skewness coefficient is 0.05 , and the kurtosis coefficient is -0.92 in the job insecurity scale. The skewness coefficient is -0.83 and the kurtosis coefficient is 0.68 in school effectiveness scale. The above data is in line with the standard, indicating that the data of each scale conforms to the normal distribution (Kline, 1998). This study examined the absolute fit index 2/df, RMR, incremental fit index NFI, CFI, RFI, simplification fit indicator PNFI, PCFI of the three scales. It can be seen from Table 1 that owing to the number of samples, the data in the three scales is slightly larger than 5. Other indicators such as RMR, NFI, CFI, RFI, PNFI, PCFI show that the three scales have good fitness (Hair, Anderson, Tatham, \& Black, 1998; Lomax \& Schumacker, 2004).

The reliability of each scale was tested using Cronbach's a value. The results are shown in Table 2. According to the Nunnally (1978) standard, the scale has good reliability when the Cronbach's a coefficient is more than 0.8; according to (Bagozzi \& Yi, 1988) standard, the CR value is more than 0.7 and the AVE value is more than 0.5 of the potential variables in the scale, indicating that the scale has good convergence validity. From the results in Table 2, it can be seen that the factor load of all the items in the questionnaires is greater than 0.5, the combined reliability $C R$ values of all dimensions are greater than 0.7 , and the average variation extraction AVE values are greater than 0.5 in all dimensions; and Cronbach's a coefficient is greater than 0.8 in all dimensions. It shows that the tools of this study have good reliability and validity.

\section{RESULTS ANALYSIS}

\section{Analysis of Current Situation}

Through the analysis of the mean value and standard deviation, the score of teacher perceived principal's positive leadership is $\mathrm{M}=4.29, \mathrm{SD}=0.82$, the score of teachers' job insecurity is $\mathrm{M}=2.49, \mathrm{SD}=0.97$, and the score of teacher perceived school effectiveness is $\mathrm{M}=4.05, \mathrm{SD}=0.83$, indicating that in this sampling, the degree of teachers 
Table 3. Summary Table of Correlation Analysis

\begin{tabular}{lcccc}
\hline Variables & $\mathbf{M} \pm \mathbf{S D}$ & Positive Leadership & Job Insecurity & School Effectiveness \\
\hline Positive Leadership & $4.29 \pm .82$ & 1 & & \\
\hline Job Insecurity & $2.49 \pm .97$ & $-.395^{\star \star \star}$ & 1 & \\
\hline School Effectiveness & $4.05 \pm .83$ & $.671^{\star \star \star}$ & $-.370^{\star \star \star}$ & \\
\hline Subscript: ${ }^{*} p<0.05 ;{ }^{* \star} p<0.01 ;{ }^{* \star *} p<0.001$ & & &
\end{tabular}

Table 4. Analysis Table of Direct Effect and Moderating Effect

\begin{tabular}{|c|c|c|c|c|}
\hline \multirow[b]{2}{*}{ Variable } & \multicolumn{4}{|c|}{ School Effectiveness } \\
\hline & Model 1 & Model 2 & Model 3 & Model 4 \\
\hline Male Teacher & -.019 & $-.106^{*}$ & .001 & -.005 \\
\hline Assistant & $.267^{\star \star \star}$ & $.203^{* *}$ & $.274^{\star \star *}$ & $.261^{\star \star \star}$ \\
\hline Lecture & $.142^{*}$ & .061 & $.155^{\star *}$ & $.160^{\star \star}$ \\
\hline Associate Professor & $.112^{*}$ & .029 & $.117^{\star \star}$ & $.104^{*}$ \\
\hline Positive Leadership & $.674^{* * *}$ & - & $.631^{* * *}$ & $.653^{\star * \star}$ \\
\hline Job Insecurity & - & $-.340^{\star \star \star}$ & $-.125^{\star \star}$ & $-.080^{\star}$ \\
\hline Interaction & - & - & - & $-.118^{\star \star}$ \\
\hline $\mathrm{R} 2$ & .483 & .176 & .496 & .507 \\
\hline Adj R2 & .477 & .166 & .489 & .499 \\
\hline$\Delta \mathrm{R} 2$ & - & - & .013 & .024 \\
\hline $\mathrm{F}$ & $81.206^{\star * *}$ & $18.557^{\star \star \star}$ & $71.076^{\star \star \star}$ & $63.696^{* * *}$ \\
\hline$d f$ & 5 & 5 & 6 & 7 \\
\hline
\end{tabular}

Subscript 1: ${ }^{*} p<0.05 ;{ }^{* *} p<0.01 ;{ }^{* * *} p<0.001$

Subscript 2: control variables such as female teacher and full professor are set as the control group

perceived principal's positive leadership is higher in private colleges and universities, the degree of job insecurity is moderate, and the degree of perceived school effectiveness is higher. It can be seen that though the degree of teachers perceived principal's positive leadership is high in colleges and universities in China, a certain degree of job insecurity still exists, and it may be caused by the fierce competition in private colleges and universities. As is shown in Table 2.

\section{Correlation Analysis}

Through the analysis of Pearson correlation coefficient, the results show that teacher perceived principal's positive leadership is positively related to school effectiveness, that job insecurity is negatively related to the teacher perceived principal's positive leadership, and that job insecurity is negatively related to the teacher perceived school effectiveness (See Table 3).

\section{Regression Analysis}

This study analyzed the direct effect and the adjustment effect. In this study, gender and professional title are converted into dummy variables and put into the regression equation. Since Table 3 is a regression analysis of direct effects and adjustment effects, a collinearity test was performed in this study when conducting regression analysis. The VIF of each model is less than 10, indicating that there is no collinearity in this study.

The specific steps are as the following: First, the principal's positive leadership and job insecurity are standardized, and then the interaction variable is set between the principal's positive leadership and job insecurity. After controlling the relevant demographic variable, the standardized positive leadership score is placed on the first layer, the standardized job insecurity score is placed on the second layer, and the interaction variable that the standardized positive leadership multiplying standardized job insecurity produces is placed on the third layer of the regression equation, and then all the above layers are conducted for hierarchical regression (Wen, Hou, \& Zhang, 2005).

\section{The direct effect of teacher perceived principal's positive leadership and job insecurity on school effectiveness}

Mode 1 and Mode 2 in Table 4 are the regression analysis of the teacher perceived principal's positive leadership and job insecurity on school effectiveness. It can be seen from Mode 1 that the regression model of teacher perceived principal's positive leadership is significant on the school effectiveness ( $\mathrm{F}=81.206, p<0.000)$, with the explanatory power of $48.3 \%$ and the standardized regression coefficient of positive leadership $(\beta=0.674, p<0.000)$. Therefore, H1 


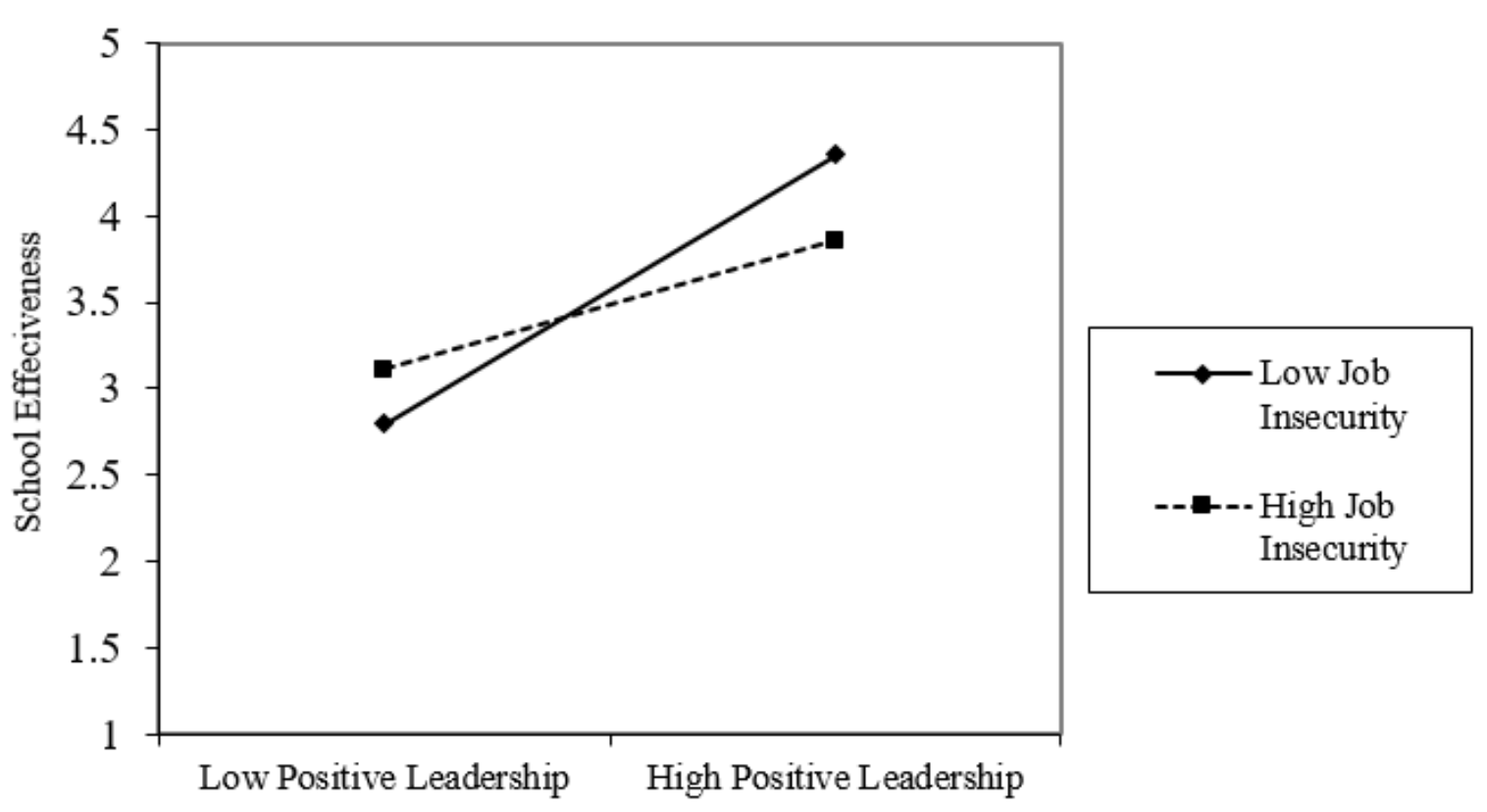

Figure 2. The Moderating Effect Diagram of Job Insecurity

is proved, and the teacher perceived principal's positive leadership has a significant positive impact on the school effectiveness.

According to Mode 2, the teachers' job insecurity has a significant regression for school effectiveness $(\mathrm{F}=18.557$, $p<0.000)$, with the explanatory power of $17.6 \%$ and the standardized regression coefficient of work insecurity $(\beta=-$ $0.340, p<0.000$ ). Therefore, $\mathrm{H} 2$ is proved, and the job insecurity of teachers in private colleges and universities has a significant negative impact on school effectiveness.

\section{The moderating role of job insecurity between teacher perceived principal's positive leadership and school effectiveness}

Mode 1, Mode 3, and Mode 4 mainly discuss the moderating effect of job insecurity. And the moderating effect analysis mainly relies on the test methods for moderation which are proposed by Baron and Kenny (1986). The moderating effect should meet three conditions: A. The independent variable has a significant predictive effect on the dependent variable; $\mathrm{B}$. The moderator variable has a significant predictive effect on the dependent variable; $\mathrm{C}$. The interaction variable of independent variable and moderator variable has significant predictive effects on the dependent variable.

In Model 4, when the interaction variable is put into the model, the regression of the interaction variable to school effectiveness is significant $(\mathrm{F}=58.804, p<0.000)$, with the explanatory power of $50.7 \%$ and the normalized regression coefficient of interaction item $(\beta=-0.118, p<0.000)$. It shows that the interaction of teacher perceived principal's positive leadership and job insecurity has a significant impact on the school effectiveness. Therefore, $\mathrm{H} 3$ is proved, and teachers' job insecurity in private colleges and universities has a moderating role between teacher perceived principal's positive leadership and school effectiveness.

In order to better highlight the role of job insecurity in negatively moderating the relationship between teacher perceived principal's positive leadership and school effectiveness, the moderating effect diagram, Figure 2, was drawn in this study according to the regression analysis. The results show that the slope of low job insecurity is greater than the slope of high job insecurity, but there is an intersection between them. That is, when teachers perceived principal's positive leadership is high, teachers with high job insecurity will feel lower school performance than teachers with low insecurity. However, when teachers perceived principal's positive leadership is low, teachers with high job insecurity will feel higher school effectiveness than teachers with low job insecurity.

\section{CONCLUSION AND DISCUSSION}

\section{Conclusion}

This study verified the Theory of Social Information Processing (Salancik \& Pfeffer, 1978) and drew the following conclusions: teachers perceived principal's positive leadership in private colleges and universities has a 
positive influence on school effectiveness; the job insecurity of the teachers in private colleges and universities has a negative impact on school effectiveness; the sense of job insecurity has a moderating role in the leadership of teachers perceived principal's positive leadership and school effectiveness in private colleges and universities.

\section{Discussion}

\section{Teachers perceived principal's positive leadership has a positive impact on school effectiveness}

The results of this study show that the higher the degree of teachers perceived principal's positive leadership, the better the degree of perceived school effectiveness, which is consistent with the research results of Wu (2013), $\mathrm{Li} \mathrm{(2012)}$ and Xie (2011). It also echoes that positive leadership can create a performance that is beyond normal or expected standards, and lead to an increase in productivity, profitability, and quality of the organization (Cameron, 2013). In the specific analysis, that teachers perceive the principal can share the lofty ideals of school education, combine the core values of the school with the personal values of the teachers, and clearly present the positive meaning of the working goals when planning the school vision are the most important factors to directly improve the school effectiveness. It guides teachers to maintain positive emotions, form a positive atmosphere in the team, and guide the teachers to get along with each other, find each other's strengths, and stimulate the potential of members and organizations so as to further promote a virtuous circle of positive relationships.

\section{Teachers' job insecurity has negative influence on school effectiveness}

The results of this study show that the higher the degree of job insecurity among teachers, the lower the degree of perceived school effectiveness, which is consistent with the findings of Zhao and Liang (2015), Bemtson, Naswall, and Sverke (2010) and Lam, Liang, Ashford, and Lee (2015). It can be seen that the job insecurity of teachers in private colleges and universities is an important factor influencing teacher perceived school effectiveness. Reducing teachers' job insecurity can effectively improve teachers' perceived school effectiveness.

\section{The moderating effect}

The results of this study show that job insecurity has a moderating role between the teacher perceived principal's positive leadership and school effectiveness, indicating that job insecurity can serve as a moderating variable. The results are consistent with the findings of $\mathrm{Hu}$ and $\mathrm{Zuo}$ (2007), Li (2013), Zhang (2017). From the specific moderating effect, when teacher perceived principal's positive leadership is low, the teachers with high level of job insecurity have lower degree in perceiving school effectiveness than the teachers with low level of job insecurity. As the level of teachers perceiving principal's positive leadership rises and reaches a certain level, teachers with high levels of job insecurity are less likely to perceive school effectiveness than those with low levels of job insecurity, indicating that job insecurity has a higher moderating effect on teacher perceived principal's positive leadership. This further echoes the two-factor theory that job insecurity is a protective factor for teachers' work. When teachers perceive that their jobs are not guaranteed or far from the principal's requirements, job insecurity will affect their work mood and attitude, working efficiency, and ultimately the overall school effectiveness (Herzberg et al., 1959). This study found that when the degree of teacher perceived principal's positive leadership is low, teachers with low job insecurity are less likely to perceive the school effectiveness than teachers with high job insecurity. The reason may be that teachers with low job insecurity cast their feelings about the principal's positive leadership on school effectiveness. They think that a school with poor leadership can't show high efficiency (Blau \& Presser, 2013; Hu \& Huang, 2007; Lukaš \& Jankovic, 2014). On the contrary, teachers with high job insecurity are more likely to perceive higher school effectiveness. The reason may be that such teachers are more sensitive and cautious in working. They believe that the reason for the high efficiency of the school may come from good institutions and high-quality faculty (Chin \& Chuang, 2015), not entirely from the influence of the principal's leadership.

It can be seen that in school management, if teacher perceived principal's positive leadership is higher, the principal can improve the school effectiveness through moderating the job insecurity. Therefore, in school affairs, the principal can help the teachers reduce their sense of job insecurity and improve their perceived school effectiveness by shaping positive atmosphere, establishing positive relationships, adopting positive communication, and demonstrating positive meanings. 


\section{Study Recommendations}

According to the results of this study, the teacher perceived principal's positive leadership can positively affect the school effectiveness; job insecurity can moderate the effect of teacher perceived principal's positive leadership on the school effectiveness. Therefore, the following recommendations are proposed in this study:

(1) Recommendations to the principals of private colleges and universities. In the actual school administration, the school goals can be achieved by using positive leadership decision-making, developing the positive leadership, taking the lead by the leader himself, listening to the teachers' expectations with empathy, caring about every teacher, trying to meet the teachers' work needs, helping them in self-realization, and reducing their job insecurity.

(2) Recommendations to education administrations. Positive leadership should be strengthened in school principals of private colleges and universities, such as holding a principal leadership training course. College principals should be encouraged to actively adopt the positive leadership in school administrations, communicate with teachers with positive emotions and thinking, and then establish positive interpersonal relationships. It is better to try to meet the needs of teachers in their work and help teachers to achieve themselves. At the same time, multiple perspectives should be introduced to evaluate school effectiveness, actively carry out exchanges of administration experience in private colleges and universities, and jointly improve the effectiveness of them.

(3) Recommendations to future studies. More scientific and rigorous sampling methods should be introduced into subsequent studies. It is also suggested to expand the sample source so as to make the samples more representative, and to improve external validity to enhance the persuasiveness and credibility of the conclusion. Questionnaires should be used to extract subjects from investigations for interviews or experiments. And the qualitative research, quantitative research, and experimental research are supposed to be combined, so as to improve internal validity.

\section{REFERENCES}

Abdullah, M. C. (2009). Leadership and PsyCap: A study of the relationship between positive leadership behaviors and followers' positive psychological capital (Doctoral Dissertation), Capella University.

Ashford, S. J., \& Bobko, P. (1989). Content, cause, and consequence of job insecurity: a theory-based measure and substantive test. Academy of Management Journal, 32(4), 803-829.

Bagozzi, R. P., \& Yi, Y. (1988). On the evaluation of structural equation models. Journal of the academy of marketing science, 16(1), 74-94. https:/ / doi.org/10.1007/BF02723327

Baron, R. M., \& Kenny, D. A. (1986). The moderator-mediator variable distinction in social psychological research: Conceptual, strategic, and statistical considerations. Journal of Personality and Social Psychology, 51(6), 11731182. https:// doi.org/10.1037/0022-3514.51.6.1173

Berntson, E., Naswall, K., \& Sverke, M. (2010). The moderating role of employability in the association between job insecurity and exit, voice, loyalty and neglect. Economic and Industrial Democracy, 31(2), 215-230. https:/ / doi.org/10.1177/0143831X09358374

Blau, I., \& Presser, O. (2013). E-Leadership of school principals: Increasing school effectiveness by a school data management system. British Journal of Educational Technology, 44(6), 1000-1011. https:/ / doi.org/10.1111/bjet.12088

Cameron, K. S. (2008). Positive Leadership: Strategies for Extraordinary Performance. San Francisco SF, USA: BerrettKoehler Publishers, Inc.

Cameron, K. S. (2012). Positive Leadership: Strategies for Extraordinary Performance (2th ed.). San Francisco, CA: BerrettKoehler. Coincident with changes in student achievement. East Lasing: Michigan State consequences. Journal of Organizational Behavior, 11(5), 345-359.

Chen, M. (2019). Research on the Relationship between College Teachers' Job Insecurity, Job Burnout and Organizational Support. Education Review, (1), 122-127.

Chin, J. M. C., \& Chuang, C. P. (2015). The Relationships among School-Based Budgeting, Innovative Management, and School Effectiveness: A Study on Specialist Schools in Taiwan. The Asia-Pacific Education Researcher, 24(4), 679-693. https:/ / doi.org/10.1007/s40299-014-0220-3

Donaldson, S. I., \& Ko, I. (2010). Positive organizational psychology, behavior, and scholarship: A review of the emerging literature and evidence base. Journal of Positive Psychology, 5(3), 177-191. https://doi.org/10.1080/17439761003790930

Feng, D. D., Lu, C. Q., \& Xiao, A. L. (2008). The relationship between job insecurity and happiness, performance: the role of self-efficacy. Psychological Bulletin, 40(4), 448-455. https:/ / doi.org/10.3724/SP.J.1041.2008.00448 
Greenhalgh, I., \& Rosenblatt, Z. (1984). Job insecurity: toward conceptual clarity. Academy of Management Review, 9(3), 438-448. https:/ / doi.org/10.2307/258284

Hair, J. F., Anderson, R. E., Tatham, R. L., \& Black, W. C. (1998). Multivariate data analysis. 1998. Upper Saddle River.

Hellgren, J., Sverke, M., \& Isaksson, K. (1999). A two-dimensional approach to job insecurity: Consequences for employee attitudes and well-being. European Journal of Work and Organizational Psychology, 8(2), 179-195. https:/ / doi.org/10.1080/135943299398311

Hou, S. C. (2002). Research on parents' education expectations, participation in school education and school effectiveness in the National Primary School (Doctoral Thesis), Education Institute of National Taiwan Normal University, Taipei City.

Hu, L. Z, \& Huang, J. W. (2007). The research on the relationship between leadership behavior, organizational culture, knowledge management and school effectiveness of primary school principals. School Administration, 50(7), 145-166.

Hu, S. M., \& Zuo, B. (2007). Organizational Political Perception and Organizational Commitment: A Study of the Regulating Role of Work Insecurity. Psychological Exploration, (2), 82-87.

Hu, S. M., \& Zuo, B. (2007). Work insecurity and its impact on work stress, job satisfaction and performance. Chinese Journal of Clinical Psychology, 15(2), 142-145.

Jiang, T. T., \& Chen, J. C. (2011). A review of research on the impact of job insecurity. Human Resource Management, (3), 17-20.

Kaiser, H. F. (1974). An index of factor simplicity. Psychometrika, (39), 31-36. https:/ / doi.org/10.1007/BF02291575

Lam, C. F., Liang, J., Ashford, S. J., \& Lee, C. (2015). Job insecurity and organizational citizenship behavior: Exploring curvilinear and moderated relationships. Journal of Applied Psychology, 100(2), 499-510. https://doi.org/10.1037/a0038659

Li, Y. Z. (2012). A study on principal's positive leadership and school effectiveness in Xinbei primary school (Master's Thesis), National Taipei University of Education, Taipei City.

Lin, X. F. (2010a). Strategies and techniques of principal's positive leadership. National Education, 50(6), 1-7.

Lomax, R. G., \& Schumacker, R. E. (2004). A beginner's guide to structural equation modeling. New Jersey: Lawrence Erliaum Associates, Inc., Publishers. https:/ / doi.org/10.4324/9781410610904

Lukaš, M., \& Jankovic, B. (2014). Predictive Ability of Variables Related to the Aspects of School Principals' Management. Online Submission, 10(3), 657-666.

Luo, X. P., \& Zhang, X. Q. (2018). The cross-level impact of positive leadership on employee behavior: selfverification perspective. Forecast, 37(3), 7-14.

Luthans, F., Avolio, B. J., Avey, J. B., \& Norman, S. M. (2007). Positive Psychological capital: Measurement and relationship with performance and satisfaction. Personnel Psychology, 60(4), 541-572. https:// doi.org/10.1111/j.1744-6570.2007.00083.x

Piccoli, B., \& Witte, H. D. (2015). Job insecurity and emotional exhaustion: Testing psychological contract breach venus distributive injustice as indicators of lack of reciprocity. Work $\mathcal{E}$ Stresss, 29(3), 1-18. https:/ / doi.org/10.1080/02678373.2015.1075624

Qiu, J. Z. (2003). Educational vision and effectiveness. Taipei: Higher education.

Roskies, E., \& Louis-Guerin, C. (1990). Job insecurity in managers: Antecedents and consequences. Journal of Organizational Behavior, 11(5), 345-359. https://doi.org/10.1002/job.4030110503

Salancik, G. R., \& Pfeffer, J. (1978). A social information processing approach to job attitudes and task design. Administrative Science Quarterly, 23(2), 224-253. https:/ / doi.org/10.2307/2392563

Sverke, M., \& Hellgren, J. (2002). The nature of job insecurity: understanding employment uncertainty on the brink of a new millennium. Applied Psychology, 51(2), 23-42. https://doi.org/10.1111/1464-0597.0077z

Wang, Y. R., Wu, H., Wang, X., \& Wu, C. (2018). The sense of job insecurity in knowledge workers: influence and control. Scientific Management Research, (7), 186-193.

Wen, Z. L., Zhang, L., \& Hou, J. T. (2006). Moderating variables with mediation and mediating variables with moderation. Journal of Psychology, 38(03), 448-452.

Wong, Y. T., Wong, C. S., Ngo, H. Y., \& Lui, H. K. (2005). Different responses to job insecurity of Chinese workers in joint ventures and state owned enterprises. Human Relations, 58(11), 1391-1418. https:/ / doi.org/10.1177/0018726705060243

$\mathrm{Wu}$, L. Z. (2013). Positive leadership, teacher professional development and school effectiveness in Taizhong primary principals (Master's Thesis), Donghai University, Taichung City. 
Wu, Q. S. (2013). Positive leadership. Educational Research Monthly, 230, 136-137.

Xie, C. C. (2011). A study on the relationship between positive leadership and school effectiveness. Taiwan Education Development Forum, (3), 49-66.

Yu, X. Y. (2017). The concept of school effectiveness and the development of new ideas. Journal of Liaoning Education Administration College, (4), 49-53.

Zhang, L. G., Jin, T. T., \& Jiang, H. B. (2017). From outside call to taking responsibility: the influence of leadershipmember exchange on the sense of professional mission. Applied Psychology, 23(4), 355-365.

Zhang, L., Lin, Y. C., \& Zhang, L. (2014). The impact of job insecurity on emotional exhaustion - the regulatory role of social support. Research Management, (3), 91-97.

Zhang, M. L., Zhang, L. X., \& Zhu, X. W. (2009). Research on the relationship between principal's leadership and school effectiveness. Education for Chinese After-school (Theory), 10(4), 11-13.

Zhao, L. L. (2016). The influence of the principal's management communication ability on school effectiveness based on the survey of 15 middle schools. Basic Education, 13(5), 47-53.

Zhao, X., Li, M. M., \& Tan, T. T. (2007). Research on the relationship between college teachers' organizational commitment and job performance. Human Resource Management, (5), 99-100.

Zhao, Z. H., \& Liang, Y. (2015). A vertical analysis of the impact of a new employee's job insecurity on his or her performance and willingness to stay. Technological Progress and Countermeasures, 32(15), 149-155.

Zhong, X. L. (2011). The influence of positive leadership and school culture on the effectiveness of school innovation management in the National Primary School in Taiwan (Doctoral Thesis), National Taipei University of Education, Taipei City.

Zhu, P. Y., \& Hu, Y. (2014). Research on the impact of job insecurities in scientific and technological talents on innovation behavior. Scientific Research, (9), 1360-1368.

\section{http://www.ejmste.com}

